\title{
TO EVALUATE ADVANCED FLAP TECHNIQUE FOR PILONIDAL SINUS DISEASES
}

\author{
Kanwar Singh Goel1 ${ }^{1}$ Sapna Goel²
}

${ }^{1}$ Associate Professor, Department of General Surgery, SGT Medical College, SGT University, Budhera, Gurugram, Haryana. ${ }^{2}$ Assistant Professor, Department of Pathology, World College of Medical Sciences, Gurawar, Jajjhar, Haryana.

\section{ABSTRACT}

\section{BACKGROUND}

Pilonidal sinus is an epithelial-lined tract, generally situated short distance behind anus. It contains hairs and unhealthy diseased granulation tissues. It is caused by penetration of hair through skin into subcutaneous tissues. When the disease is confirmed to the midline, one option is to excise the affected area and close it in an attempt to achieve primary healing. If this fails, a large wound occurs which heals by granulation. Even if primary healing is successful the patient remains at great risk of recurrent diseases, as there is now a midline scar deep within the natal cleft through which hairs may penetrate with greater ease than through undamaged skin. Since there is no single standard operation, poor results discourage surgeons, surgeons do not promptly take up this surgery. There is late presentation because of poor awareness and illiteracy in rural areas. Infection at presentation takes longer treatment and prolonged hospitalisation. In view of all these, we have taken this series of 40 cases of treatment of pilonidal sinus by advanced flap technique for study of morbidity and recurrences.

The aim of this study is to evaluate advanced flap technique for Pilonidal sinus diseases.

\section{MATERIALS AND METHODS}

This is a case series study. Our present series comprises of 40 consecutive cases over a period of 3 years duration. Cases were divided into 3 categories- Category I, Category II and Category III. Sinus was excised by an encircling quadrangular incision. Incision was deepened from all sides till fascia and entire sinus excised. Haemostasis was achieved. Flap was raised as shown in diagram (Figure 1) and stitched after putting a closed suction drain (Figure 2).

\section{RESULTS}

There were 34 male patients and 6 were females. Mean age in Category 1 was 22 years, in Category 2 was 26 years and in Category 3 was 20 years. Post of drain removal was on $5^{\text {th }}, 6^{\text {th }}$ and $7^{\text {th }}$ day respectively in Category 1,2 and 3. Post-operative complication was wound infection requiring dressing up to 10 days in $10 \%$ cases. Wound infection requiring dressing for more than 10 days was in $17.5 \%$ cases. Recurrence was found in $7.5 \%$ cases.

\section{CONCLUSION}

Pilonidal sinus is a disease where a variety of surgical procedures have been prescribed. Not a single technique is fool proof. Search for ideal procedure is on. We at our hospital at SGT Medical College, Gurugram, are practicing advanced flap technique for a little over 3 years. Our results show that this technique is easy to practice, and results are reasonably good in terms of recurrence.

\section{KEYWORDS}

Advanced Flap, Pilonidal Sinus, Technique, Recurrence.

HOW TO CITE THIS ARTICLE: Goel KS, Goel S. To evaluate advanced flap technique for pilonidal sinus diseases. J. Evolution Med. Dent. Sci. 2018;7(08):965-968, DOI: $10.14260 /$ jemds/2018/221

\section{BACKGROUND}

Pilonidal sinus is an epithelial lined tract, short distance behind anus. It contains hairs and unhealthy diseased granulation tissues. It is because of penetration of hair through skin into s/c tissues. It forms granuloma/ unhealthy granulation tissue in the deeper plane. Types of hair, force of hair insertion into subcutaneous tissue and vulnerability of the skin are the three factors that cause pilonidal sinus. Number of hairs collected, acuteness of root end of hairs, type of hair- tough/silky, shape of hair- straight/curled and scaliness of hair are the deciding features of hair. Cut hairs from above descend into cleft and stay there to get buried

'Financial or Other Competing Interest': None.

Submission 09-01-2018, Peer Review 01-02-2018,

Acceptance 08-02-2018, Published 19-02-2018.

Corresponding Author:

Dr. Sapna Goel,

MBBS, MD, DNB (Pathology),

25/6, Opp. Bal Bhawan, Gandhi Nagar,

Scheme No. 6, Jind.

E-mail: dr.sapna02@rediffmail.com

DOI: $10.14260 /$ jemds $/ 2018 / 221$

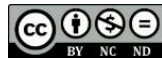

deep into pilonidal sinus. Depth, narrowness, friction movements in the natal cleft; soft/ macerated skin with erosions, splits, wide skin pores, wounds, presence of moisture and sweat are other factors. It is common in hair dressers (Seen in interdigital clefts) and jeep drivers. ${ }^{1}$ The condition is seen much more frequently in men than in women, usually after puberty and before the fourth decade of life. ${ }^{2}$ It is characteristically seen in dark- haired individuals rather than those with softer blond hair (Oldham). Its incidence is somewhere about 1.5 per 1000 population. ${ }^{3}$ It is common in males and mostly affects hairy men. Obesity, local trauma, familial predisposition, smoking and sedentary life have also been attributed in aetiology. 4,5

It is though that the combination of buttock friction and shearing force in that area allows shed hair or broken hairs which have collected there to drill through the midline skin, or that infection in relation to a hair follicle allows hair to enter the skin by the suction created by movement of buttocks, so creating a subcutaneous, chronically infected, midline track. From this primary sinus, secondary tracks may spread laterally, which may emerge at the skin as granulation tissues lined, discharging openings. Usually, but not 
invariably (when diagnosis may be confused with anal fistula or hidradenitis suppurativa), the sinus runs cephalad. Carcinoma arising in chronic pilonidal diseases has been described, but is exceedingly rare. Patients complain of intermittent pain, swelling and discharge at the base of the spine, but little in way of constitutional symptoms. There is often a history of repeated abscesses that have burst spontaneously, or which have been incised usually away from the midline. The primary sinus may have one or many openings, all of which are strictly in the midline between the level of the sacrococcygeal joint and the tip of the coccyx. ${ }^{6}$ As the natural history of the condition is usually one of regression, in those whose symptoms are relatively minor, simple cleaning out of the tracks and removal of all hair with regular shaving of the area and strict hygiene may be recommended. If rest, baths, local antiseptic dressing and the administration of a broad-spectrum antibiotic fail to bring about resolution the abscess should be drained through a small longitudinal incision made over the abscess and off the midline with thorough curettage of granulation with complete resolution. The multiple of surgical procedures advocated to eradicate pilonidal disease combined with the lack of prospective trials, attests to the lack of overall superiority of one method over the others. Time spent off work and perceived recurrence rates, but more usually surgeon preference influence the choice of method, which include the laying open of all tracks with or without marsupialisation, the excision of all tracks with or without marsupialisation, the excision of all tracks with or without primary closure and the excision of all the tracks and then closure by some other means designed to avoid a midline wound. Thus, we see that in pilonidal sinus a variety of surgical procedures have been prescribed. No one is just foolproof.7 Search for ideal procedure is on. We at our hospital at SGT Medical College, Gurugram are practicing advanced flap technique for a little over 3 years.

\section{Aims and Objective}

To evaluate advanced flap technique for Pilonidal sinus diseases.

\section{MATERIALS AND METHODS}

This is a case series study. We are presenting a series of 40 cases spread over nearly 3 years. There were 3 categories of cases-

a. Clean cases without any clinical evidence of infection.

b. Mild infection, but no purulent diseases.

c. Purulent diseases.

In all patients proper counselling regarding recurrence was done and proper informed consent was taken. The procedure was performed under spinal anaesthesia. Clean cases were managed by standard flap technique as depicted in diagram (Figure 1). Complete haemostasis was achieved. Wide bore closed suction drain of size no. 16 was put. Closure was made in two layers. Inner layer of Vicryl 000/00 depending on thickness of wound and skin layers with prolene 00. Drain was removed after 5 - 7 days. Stitches were removed after 10 - 14 days. In mild infected cases a preoperative course of antibiotics oral or IV depending on patient's choice (Amoxyclav, sometimes Linezolid- if patient has already received Amoxyclav) was given. After a gap of 1-2 weeks, the standard operation as in clean cases was done. In purulent diseases, management was done by liberal incision and drainage to allow free drainage, then regular dressing was done. After a gap of 6 - 8 weeks, standard flap technique was performed (Figure 2).

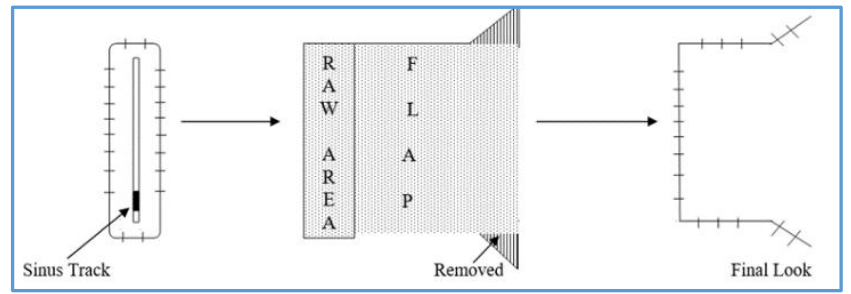

Figure 1. Schematic Representation of the Technique

Sinus was excised by encircling quadrangular incision as shown. Incision was deepened from all sides till fascia and entire sinus was excised, Haemostasis was achieved. Flap was raised. The length of flap was $1 \frac{1 / 2}{2}$ times the width of excised sinus, so that there was no tension. The flap was mobilised from fascia above. China wall dressing was applied (Figure 2). The excised sinus in all the cases was sent for histopathology exam, which revealed non-specific inflammation and granulation.

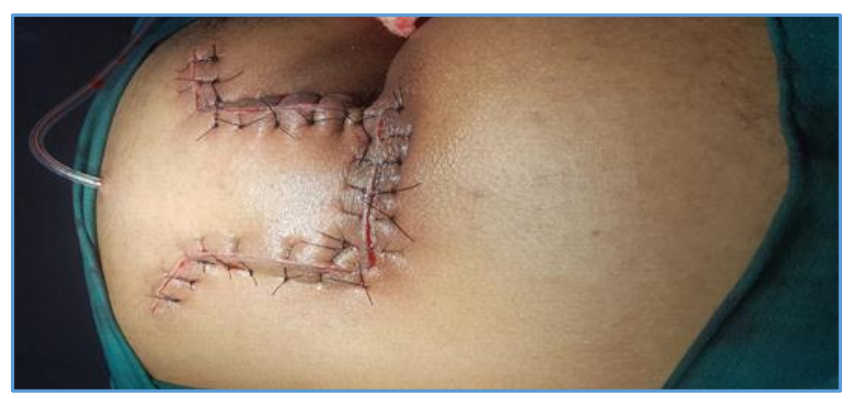

Figure 2. Post-Operative Image

\section{RESULTS}

Out of 40 patients, 26 patients were in Category I, 8 patients were in Category II and 6 patients were in Category III (Table 1). Mean age of patients were 21 and S.D. was 3.43 years in Category I; 28 and S.D. was 2.76 years in Category II and 24 and S.D. was 3.67 years in Category III (Table 2). Number of male patients were 21, 8 and 5 respectively in Categories I, II and III respectively. Number of female patients were 5, 0 and 1 respectively in categories I, II and III respectively (Table 2). In almost 3/4th patients, most of the risk factor were present. In all the patients, sinus was completely excised, and standard advanced flap technique was done. Post-op drain in $\mathrm{mL}$ averagely was $12 \mathrm{~mL}, 15 \mathrm{~mL}$ and $22 \mathrm{~mL}$ respectively in Categories I, II and III respectively (Table 3). Drain was removed when the amount was almost nil. It occurred in 5 to 7 days in all patients (Table 4). In 10\% of cases, wound infection occurred which required dressing upto 10 days. In $17.5 \%$ of cases wound infection occurred which required dressing for more than 10 days. There was recurrence in $7.5 \%$ cases (Table 5). Stiches were removed in 10 to 14 days and patients were regularly followed up for 6 months.

\begin{tabular}{|c|c|}
\hline Category & Number of Patients \\
\hline I & 26 \\
\hline II & 8 \\
\hline III & 6 \\
\hline Table 1. Showing Categorisation, $\mathbf{n = 4 0}$ \\
\hline
\end{tabular}




\begin{tabular}{|c|c|c|c|}
\hline & Category I & Category II & Category III \\
\hline Mean age in years & 21 (S.D. 3.43) & $\begin{array}{c}28 \text { (S.D. } \\
2.76)\end{array}$ & 24 (S.D. 3.67) \\
\hline $\begin{array}{c}\text { Sex } \\
\text { Male }\end{array}$ & $\begin{array}{c}21(80.76 \%) \\
5(19.34 \%)\end{array}$ & $\begin{array}{c}8(100 \%) \\
0(0 \%)\end{array}$ & $\begin{array}{c}5(83.33 \%) \\
1(16.67 \%)\end{array}$ \\
Female & \multicolumn{2}{|c|}{$\mid$}
\end{tabular}

Table 2. Showing Age and Sex Distribution

\begin{tabular}{|c|c|}
\hline Category I & $12 \mathrm{~mL}$ \\
\hline Category II & $15 \mathrm{~mL}$ \\
\hline Category III & $22 \mathrm{~mL}$ \\
\hline
\end{tabular}

\begin{tabular}{|c|c|}
\hline Post-Op Drain Removal In & Number of Patients \\
\hline 5 days & $14(35 \%)$ \\
\hline 6 days & $22(55 \%)$ \\
\hline 7 days & $4(10 \%)$ \\
\hline \multicolumn{2}{|c|}{ Table 4. Showing Post-Op Drain Removal } \\
\hline
\end{tabular}

\begin{tabular}{|c|c|}
\hline Complications/ Recurrence & Number of Patients \\
\hline $\begin{array}{l}\text { Wound Infection requiring } \\
\text { dressing upto } 10 \text { days }\end{array}$ & $4(10 \%)$ \\
\hline $\begin{array}{l}\text { Wound Infection requiring } \\
\text { dressing more than } 10 \text { days }\end{array}$ & $7(17.5 \%)$ \\
\hline Recurrence & $3(7.5 \%)$ \\
\hline \multicolumn{2}{|c|}{ Table 5. Showing Complications/Recurrence } \\
\hline
\end{tabular}

\section{DISCUSSION}

Pilonidal sinus apparently minor condition can present the surgeon with major challenges. Recent advance in treatment have focused on the avoidance of midline scar.8,9 Many of the standard surgical procedures are associated with a significant risk, both of delayed healing and of recurrent diseases. The initial pathology is of one or more tiny deep midline pits in the natal cleft, which connect with a granulation tissue lined cavity, lying in the subcutaneous fat and containing loose hairs. Later on infection extends under apparently normal skin, both in the natal cleft and laterally into one or both buttocks.10,11 Minor infections may settle on antibiotics, but if an abscess develops it will discharge or require drainage. The underlying disease however persists and repeated episode of infection are likely.10,11 Recurrent infection occurs in this cavity. ${ }^{12}$ When this fails, a large wound then has to granulate. Even if primary healing is successful the patient remains at great risk of recurrent diseases, as there is now a midline scar deep within the natal cleft through which hairs may penetrate with greater ease than through undamaged skin. ${ }^{13}$ The alternative of deroofing all sinuses, clearing hair and granulation tissue and leaving the wound open for secondary healing has the advantage that the total tissue defect is smaller than that were an excision and primary repair has broken down. ${ }^{14}$ It is also a feasible operation when the diseases extends laterally and primary closure would not be possible. The disadvantage though are of slow healing and even if this proceeds without complication, it will be at least 6 weeks before the wound has healed and epithelialized. During the healing period the granulating wound must be kept clean, any loose hairs must be removed and the surrounding skin kept shaved. All heal with a wide midline scar which is vulnerable to recurrent diseases and despite meticulous postoperative attention the occasional patient develops a persistently unhealed midline wound. ${ }^{15}$ Our flap technique has proved reasonably successful for pilonidal diseases. Excision and primary closure is a recommended procedure. It is in line with what is recommended in recent advances.

Excision and skin grafting has got high recurrence rate. Excision with $\mathrm{Z}$ plasty has good results. Excision with multiple $\mathrm{Z}$ plasty is also good. Karydakis excision through a semilateral incision and lateralised suturing of the wound away from the midline gives good results. ${ }^{16}$ Excision with closure using Limberg (Rhomboid) buttock flap (single or double rhomboid flaps) also gives good results. ${ }^{17}$ Bascom technique of excision through lateral approach is a good method. ${ }^{18}$ Lahey and Cattell's relaxing skin incision on one buttock to relieve tension on main wound suture with later closure of secondary wounds by suture or advanced. Davies and Starr buttock skin flap rotation into the defect and secondary defect closed at a later period. Some people were treated by excision of entire sinus completely. Wound is left open to granulate and heal by epithelialisation with regular dressing. In Buie's marsupialisation of the sinus tract- after making incision on the sinus tract, edge of the laid opened area is sutured to the skin edge all around using silk or vicryl. Lord and Miller's limited excision of primary tract for $0.5 \mathrm{~cm}$ depth with removal of tuft of hairs, debris and unhealthy granulation tissue using tiny brush nylon bristle. Injection of phenol to the track destroys the epithelium after removal of tufted hairs. Phenol is allowed to be in contact with epithelium for 3 minutes to create a blanch in the track orifice.

In our advanced flap technique, sinus was excised completely by encircling quadrangular incision as shown (Figure 1). Incision was deepened from all sides till fascia and entire sinus was excised. Haemostasis was achieved. Flap was raised. The length of flap was $1 \frac{1 / 2}{2}$ times the width of excised sinus, so that there was no tension. The flap was mobilised from fascia above and stitching was done (Figure 2). In our technique, post-operative complications i.e. wound infection and recurrence rate were of low volume. Further the technique is easy to practice and results are reasonably good in lines of recurrence.

\section{CONCLUSION}

Pilonidal sinus is a disease where a variety of surgical procedure have been prescribed. No one is just full proof. Search for ideal procedure is on. We at our hospital at SGT Medical College Gurugram are practicing advanced flap technique for a little over 3 years. Our results show that this technique is easy to practice and results are reasonably good in lines of recurrence.

\section{REFERENCES}

[1] Sriram Bhat M. SRB's manual of surgery. $5^{\text {th }}$ edn. New Delhi: Jaypee Brothers Medical Publishers 2016.

[2] Spivak H, Brooks VL, Nussbaum M, et al. Treatment of chronic pilonidal diseases. Dis Colon Rectum 1996;39(10):1136-9.

[3] McCallum IJ, King PM Bruce J. Healing by primary closure versus open healing after surgery for pilonidal sinus: systematic review and meta-analysis. BMJ 2008;336(7649):868-71. 
[4] Sondenna K, Anderson E, Soreide JA. Morbidity and short-term result in a randomised controlled trial of open compared to closed treatment of chronic pilonidal sinus. Eur J Surg 1992;159(6-7):351-5.

[5] Doll D, Matevossian E, Wietelmann K, et al. Family history of pilonidal sinus predisposes to earlier onset of diseases and a 50\% long-term recurrence rate. Dis Colon Rectum 2009;52(9):1610-5.

[6] Williams N, Bulstrode CJK, O'Connell PR. Bailey \& Love's short practice of surgery. $26^{\text {th }}$ edn. London: Taylor \& Francis 2013.

[7] Muller K, Marti L, Tarantino I, et al. Prospective analysis of cosmetic, morbidity and patient satisfaction following Limberg flap for the treatment of sacrococcygeal pilonidal sinus. Dis Colon Rectum 2011;54(4):487-94.

[8] Kitchen PR. Pilonidal sinus: experience with the Karydakis flap. Br J Surg 1996;83(10):1452-5.

[9] Tekin A. Pilonidal sinus: experience with Limberg flap. Colorectal Dis 1999;1(1):29-33.

[10] Sondenaa K, Pollard ML. Histology of chronic pilonidal sinus. APMIS 1995;103(4):267-72.

[11] Lorant T, Ribbe I, Mahteme H, et al. Sinus excision and primary closure versus laying open in pilonidal diseases: a prospective randomized trial. Dis Colon Rectum 2011;54(3):300-5.
[12] el-Khadrawy O, Hashish M, Ismail K, et al. Outcome of the rhomboid flap for recurrent pilonidal diseases. World J Surg 2009;33(5):1064-8.

[13] Mahdy T. Surgical treatment of the pilonidal diseases: primary closure or flap reconstruction after excision. Dis Colon Rectum 2008;51(12):1816-22.

[14] Gencosmanoglu R, Inceoglu R. Modified lay-open (incision, curettage, partial lateral wall excision and marsupialization) versus total excision with primary closure in the treatment of chronic sacrococcygeal pilonidal sinus: a prospective, randomized clinical trial with a complete two-year follow-up. Int J Colorectal Dis 2005;20(5):415-22.

[15] Farquharson M, Moran B. Farquharson's textbook of operative general surgery. $9^{\text {th }}$ edn. London: Hodder Arnold 2005.

[16] Karydakis GE. Easy and successful treatment of pilonidal sinus after explanation of its causative process. Aust N Z J Surg 1992;62(5):385-9.

[17] Onder A, Girgin S, Kapan M, et al. Pilonidal sinus diseases: risk factors for postoperative complication and recurrence. Int Surg 2012;97(3):224-9.

[18] Bascom J. Pilonidal diseases: origin from follicle of hairs and results of follicle removal as treatment. Surgery 1980;87(5):567-72. 